\title{
Research on Tourism Commodity Development of Shandong Province Based on Traditional Tea Culture
}

\author{
Wei Yue $e^{1, a}$ \\ ${ }^{1}$ Tourism School, Shandong Women's University, Jinan, Shandong, P.R. China \\ ayuxiaoyingtong@163.com
}

Keywords: tourism commodity development, traditional tea culture, Shandong Province.

\begin{abstract}
The development of tea culture in Shandong Province is very rapid, but there are few tea culture tourism commodities that can meet the needs of tourism consumers. Therefore, it is necessary to develop tea culture tourism commodities. At present, there are some problems in the development of tea culture tourism products in Shandong Province, such as single category, lack of cultural connotation, inadequate publicity and lack of brand awareness. In view of the above problems, to develop appropriate tea culture tourism commodities, we should enhance cultural connotation, pay attention to brand development and enrich commodity types.
\end{abstract}

\section{Introduction}

In recent years, Chinese outbound tourists have shown strong purchasing power overseas, while in comparison, China's tourism shopping accounts for less than $30 \%$ of the total tourism consumption. The proportion of foreign exchange earned by tourism commodities in the total income of tourism economy is one of the important indexes to measure the economic benefits of tourism in this region. From the perspective of tourists, purchasing tourism commodities is an indispensable part of their tourism activities, which can meet their spiritual needs. Shandong Province is China's major tourism province, but there are still many problems and unreasonable factors in the process of transforming the advantages of tourism cultural resources into industrial advantages. How to correctly grasp the opportunity of the development of China's cultural industry and develop marketable tourism products has become a new task for the development of tourism industry in Shandong Province.

Since 2014, China's tea culture tourism has shown a trend of spurt. Due to the topographical advantages of Shandong Province, tea culture tourism has a unique resource advantage compared with other provinces of the same latitude, and tea culture tourism is also booming. Under the situation that the tea culture tourism in Shandong Province is booming, the development of tea culture tourism commodities with distinctive humanistic characteristics of tourism destinations is very urgent and necessary in tourism consumption, and has great market development potential and business opportunities. However, the existing tea culture tourism products have the disadvantages of short development time, few varieties of development, lack of cultural characteristics, and chaotic marketing. The tea culture tourism products that reflect the profound traditional cultural connotation of Shandong Province are rare, simply can't meet the demand of tea culture tourism consumers for travel business. Therefore, based on the needs of tourism consumers, it is necessary to research and develop tea culture tourism commodities that are marketable.

\section{Research status and development trend at home and abroad}

\subsection{Tourism commodity development research}

There have been many disputes over the definition of tourism commodities. Scholars have reached a consensus on their "allopatry" and "tangible", believing that tourism commodities are tangible commodities purchased by tourists in different places. ${ }^{[1]}$ Some scholars have concluded the conceptual definition of tourism commodities in three different dimensions: demander, supplier and commodity circulation. In the dimension of demander, tourism commodities refer to tangible commodities purchased by tourists in tourism activities. In the dimension of supplier, tourism 
commodities refer to tangible commodities supplied by tourism production system with the connotation of "tourism". In the dimension of commodity circulation, tourism commodities refer to tangible commodities circulating in the open market for tourists. The definition of different dimensions is different because of the "roles" and "relationships" connected by goods. ${ }^{[2]}$ All kinds of tourism commodities reflect the unique cultural connotation of the tourism destination, and have a considerable level of craftsmanship. They preserve the tourists' commemoration of a pleasant tourism experience and have certain appreciation value, use value and collection value. At present, China's research on the development of tourism commodities mainly focuses on the problems and countermeasures in the development of tourist souvenirs, and the principles and models of tourism commodity development. The advantage of these studies is that their research is highly targeted. Through the deep exploration of real problems, the crux of these problems is found and corresponding countermeasures are proposed.

The study of tourism business in foreign countries is earlier, and the methods and means of research on tourism commodities are also diverse, including qualitative research and quantitative research. Although these studies have different emphases, most of them focus on the clue of local culture and emotional significance to tourists carried by commodities, which reflects foreign scholars' profound understanding of the connotation of tourism commodities. ${ }^{[3]}$ Both in theory and case study, foreign countries have made more achievements than China.

\subsection{Tea Culture and Tea Culture Tourism Research}

Judging from the formation system of tea culture, the application history of tea has been very long since the pre-Qin period. Of course, with the development of tea culture for more than a thousand years, the content contained in it has become increasingly rich, such as tea poetry, tea painting art, etc., which are vivid manifestations of the tea culture system. What's more, the tea culture system is also deeply integrated with values and cultural concepts, which makes the whole tea culture develop into an important interpretation and vivid expression of the world cultural system. With tea culture elements system of the inheritance and development for thousands of years, the value connotation and expression of the whole tea culture element system has realized the essential expansion and connotation extension. More importantly, in this process, the expression of tea culture is also with the innovation and deep development, combined with the characteristics of the current era and the application environment, the mentality and humanistic spirit advocated in the tea culture elements are precisely the basic factors for us to recognize traditional culture.

"Tea Culture Tourism" is a new term born under the phenomenon of tea and tourism industry integration. At present, China's research on tea culture tourism mainly focuses on the following three aspects. First, the development of tea culture tourism resources. Second, the study of the fusion mechanism of tea brigades. Third, the study of the fusion model of tea brigade. Different scholars proposed different tea-bred integration models from the perspectives of the nature of leading industries, the integration of tea tourism and the combination of tourism product forms, and the initiative of industrial integration.

\section{Problems in the development of tea culture commodities in Shandong Province}

At present, the tea culture tourism in Shandong Province has developed. The main problems in the development of tea culture tourism commodities are as follows: First, the types of tea culture tourism commodities are single, mainly based on local tea. Second, tea culture tourism commodities lack cultural connotation and fail to reflect the profound cultural heritage of Shandong Province. Third, the lack of awareness of branding and the lack of publicity have led to the failure of Shandong Province's tea culture tourism commodities to form their own brands. Fourth, the lack of awareness of independent innovation has led to competition for homogenized commodities in the tea culture commodity market in the province. 


\section{Suggestions on the development of tea culture commodities in Shandong Province}

\subsection{Enhance the cultural connotation of tea tourism commodities}

Tea culture is an important branch of China's cultural system, and the cultural leaching of tea garden tourism construction is this unique tea culture. Therefore, in the process of designing tea products, tourism enterprises must not only achieve the purpose of obtaining economic benefits, but also realize local promotion. Tea culture, based on deep tea culture, enhances the cultural connotation of tea tourism commodities, which is an important way to realize its social benefits. Shandong Province has a long history and profound cultural heritage. It is also the birthplace of Confucian culture. Shandong traditional culture has a deep influence in today's society and even in the world. It integrates traditional culture and tea culture. In the tea tourism commodities, it has enhanced its cultural connotation and realized the organic combination of the commercial value and cultural value of the tea culture tourism commodities.

\subsection{Focus on brand development, highlighting the differences in tea culture tourism commodities}

Brand design is the basis for improving recognition of the product market. In the process of developing tea culture tourism commodity brands, in addition to quality, we must also pay attention to the design of outer packaging. Under the guidance of modern design concepts, the outer packaging of tea culture tourism commodities must conform to the concept of green environmental protection and infiltrate the elements of tea culture. Such packaging can make a deep impression on consumers. In the process of building a tea brand, on the one hand, we can start with the packaging style, abandon the flashy packaging style, return to the pure and simple nature of tea, and reduce the shopping burden of consumers. On the other hand, it can be related to the tea culture of celebrity anecdotes from Shandong Province, for example, the story of the famous female poet Li Qingzhao in the Northern Song Dynasty and her husband Zhao Mingcheng gambling on tea, presenting these stories in a package, so that the brand design not only inherits the long history of tea culture in China, but also promotes the development of tea culture tourism economy.

\subsection{Enrich the variety of commodities to create the overall image of tea culture tourism commodities}

A wide variety of commodities can improve the market competitiveness of the brand and meet the needs of diversified consumers. Tea culture tourism commodities should have a breakthrough in the types and forms, from tea food, refreshments to derivatives of traditional tea culture, to form a reasonable series of commodities, to create the overall image of tea culture tourism commodities. In addition to a single tea, it can be combined with local characteristics to develop teas suitable for modern fast-paced life and modern young people's tastes, such as teabags and corporate culture, to design cultural derivatives with distinctive characteristics and portability. Enrich the variety of products and create a complete image of the complete cultural tourism commodities.

\section{Summary}

In short, the development of tea culture tourism commodities can not only promote the economic development of tea towns and obtain good economic benefits, but also meet the needs of consumers, find a tangible carrier for the inheritance of traditional tea culture, and promote the organic combination of the commercial value and cultural value of tea culture tourism commodities.

\section{References}

[1] MIAO Xueling, Tourism merchandise and souvenirs: Discussion on the conceptual definitions and local features, Tourism Tribune, vol.19, pp. 27-31,2004.

[2] LU Kaixiang, BAO Jigang, The Conceptual Definition and Research Framework of Tourism Commodity, Tourism Tribune, vol.32, pp. 116-126,2017. 
[3] WEN Hong, LI Jun, LI Yang, A Summary Research and Enlightenment of Foreign Tourist Souvenir Study, Tourism Research, vol. 8, pp. 28-34,2016. 